\title{
REESTRUTURAÇÃO DO PROGRAMA DE USO PÚBLICO E EDUCAÇÃO AMBIENTAL DO PARQUE ESTADUAL DO MORRO DO DIABO (SP)
}

\author{
Andréa Soares Pires ${ }^{1}$ \\ Helder Henrique de Faria ${ }^{2}$
}

Resumo: Este trabalho pretende contribuir para as pessoas que desejam trabalhar seriamente com o uso público e educação ambiental em áreas protegidas da IUCN categoria II, que no neste caso é o Parque Estadual do Morro do Diabo, uma área de reserva protegida e tornou-se um parque em 1986, pouco tempo depois sendo aberta ao público. Desde então, o parque apresentou atividades educacionais, mas nunca na forma de um programa de gestão estruturado. Assim, parte da análise do cenário existente em 2004 e com o envolvimento de pessoas e organizações para planejar e executar uma lógica de intervenção destina-se a estruturação do programa de uso público do parque, resultando em uma série de ações estratégicas e atividades que são relatados aqui.

Palavras-chave: Uso Público; Unidade de Conservação; Educação Ambiental.

${ }^{1}$ Instituto Florestal - Parque Estadual do Morro do Diabo. E-mail: deapires@yahoo.com.br

${ }^{2}$ Instituto Florestal - Parque Estadual do Morro do Diabo. E-mail: helderdefaria@gmail.com 


\section{Introdução}

É incontestável a importância dos recursos naturais e da biodiversidade para a humanidade. O desafio reside em tentar, a todo custo, salvar o pouco que ainda resta de natureza pouco tocada lançando mão das estratégias possíveis e imagináveis no afã de se lograr, ao menos, a sustentabilidade local e regional (Faria, 2004). A preocupação com o futuro do planeta e as medidas de combate à degradação de seus recursos vem sendo evidenciada ao longo de décadas através de conferências e protocolos internacionais, além de uma cobrança crescente da sociedade pela conservação de áreas com algum valor ambiental.

Frente à realidade mundial, em que apesar dos avanços para a conservação da natureza obtidos nas últimas décadas, com um aumento de $8,8 \%$ para $12,7 \%$ do percentual global de áreas protegidas terrestres (IUCN,2010), longe ainda dos 17\% estabelecido nas Metas de Aichi, em 2010, sobre a Convenção da Diversidade Biológica. O planeta continua a ser castigado pelo rolo avassalador do desenvolvimento insustentável (em face do perigo do aquecimento global), Loureiro (2005) entende a necessidade de formar indivíduos pensantes que atuem como agentes propagadores de um modo de vida responsável e sustentável e, neste sentido, os parques assumem papel complementar na conscientização dos cidadãos que adentram suas paisagens. As áreas protegidas da categoria Parque Nacional, de conformidade com o Sistema Nacional de Unidades de Conservação da Natureza (BRASIL, 2000) e classificado no grupo II da União Mundial para a Conservação (IUCN, 1998), têm como objetivos principais o resguardo da integridade do ecossistema para fins educacionais, recreativos e científicos, sendo que o estabelecimento de um programa de uso público pode ser importante ferramenta para a gestão eficaz da área (IBAMA, 1996; MILANO, 1999; INDRUSIAK, 2000; CGEAM, 2007).

De modo geral, a visitação em áreas protegidas objetiva propiciar um contato maior das pessoas com a natureza. Considerando que há uma grande variedade de público e oportunidades para o desenvolvimento de atividades alternativas em ambientes naturais, os programas de uso público dos Parques precisam conciliar a satisfação do visitante com a conservação destes ambientes (TAKAHASHI, 1998), o que se obtém mediante o zoneamento e planejamento ambiental da área (Miller, 1980), ademais de outros estudos correlatos (monitoramento do perfil dos visitantes, qualidade ou degradação dos recursos ambientais, capacidade de carga, manejo do visitante etc.).

Entretanto, a análise de programas de uso público em áreas protegidas brasileiras (MENGHINI et.al., 2007) evidencia que muitos gestores os entendem como sendo a prática esporádica de atividades de educação ambiental, com objetivos amplos e pautados em tratados nacionais (Programa Nacional de Educação Ambiental - ProNEA) e mundiais, mas desviando o foco do que poderia vir a ser um programa integrador e conciliador da educação na e a respeito da natureza protegida e seus viés com a temática ambiental do mundo real (VALENTI et all, 2012). Ou seja, há certa confusão programática porque os 
conceitos de 'educação ambiental' e 'programa de uso público' são tratados como equivalentes, o que de fato é impossível. Por outro lado, muitas vezes falta planejamento adequado e não se considera a gama de fatores endógenos e exógenos inerentes à gestão das áreas, como por exemplo o perfil do público alvo, resultando fracassos em alcançar os objetivos propostos (LOUREIRO, 2004; QUINTAS, 2002; SAMMARCO, 2009).

A educação ambiental se constitui numa forma abrangente de educação, que se propõe atingir todos os cidadãos, através de um processo pedagógico participativo permanente que procura incutir no educando uma consciência crítica sobre a problemática ambiental, promovendo simultaneamente o desenvolvimento de conhecimento, de atitudes e de habilidades necessárias à preservação e melhoria da qualidade ambiental. A educação ambiental que é desenvolvida em áreas protegidas é denominada 'não formal', sendo suas atividades ordenadas de acordo com o plano de manejo da área (MAYER, 1998; JACOBI, 2003).

Incluir a educação e a interpretação ambientais como elemento base dos programas de uso público é a chave para o sucesso, pois quando as atividades desses dois subprogramas são gerenciadas respeitando-se os princípios fundamentais que regem a existência da área protegida, podem promover a diversificação da economia regional, geração de empregos e renda local, melhoramento na infraestrutura de transporte, comunicações, além de contribuir com a conscientização pública sobre o valor das áreas protegidas (BRASIL, 1994; MAGRO, 1999).

Estamos envolvidos com o novo paradigma de gestão de áreas protegidas, que expressa que a dimensão humana é uma parte decisiva de qualquer estratégia para que a conservação possa chegar aos seus fins. (PIRES e FARIA, 2013). Nesse sentido MCNEELY e SCHUTYSER (2003, p.21) preconizam que a sobrevivência de muitas áreas protegidas depende de maior igualdade, não só de informações como participação direta das decisões, para que o "público em geral possa receber seus benefícios e não vê-las como lugar de diversão para os ricos e pessoas que não tem interesse em comunidades locais."

Esta abordagem de MCNEELY e SCHUTYSER (2003) foi adotada pela administração do Parque Estadual do Morro do Diabo no período compreendido entre 2004 e 2012, quando se instaurou uma dinâmica de trabalho sob a égide do lema "Popularizar para Conservar", que visou resgatar o verdadeiro valor desta importante área protegida brasileira mediante a reestruturação do seu programa de uso público-PUP, experiência que pretendemos relatar no presente artigo. 


\section{A Área Protegida}

O Parque Estadual do Morro do Diabo (PEMD) preserva a maior área contínua de floresta tropical semi-decidual do mundo (KAGEYAMA, 2009 comunicação pessoal), é zona core da Reserva da Biosfera da Mata Atlântica (IF, 2006) e uma importante área protegida nos domínios da Floresta Atlântica brasileira (Figura 1), um dos hotspots de biodiversidade do mundo, áreas que detém elevada taxa de endemismo É zona core da Reserva da Biosfera da Mata Atlântica brasileira (INSTITUTO FLORESTAL, 2006).

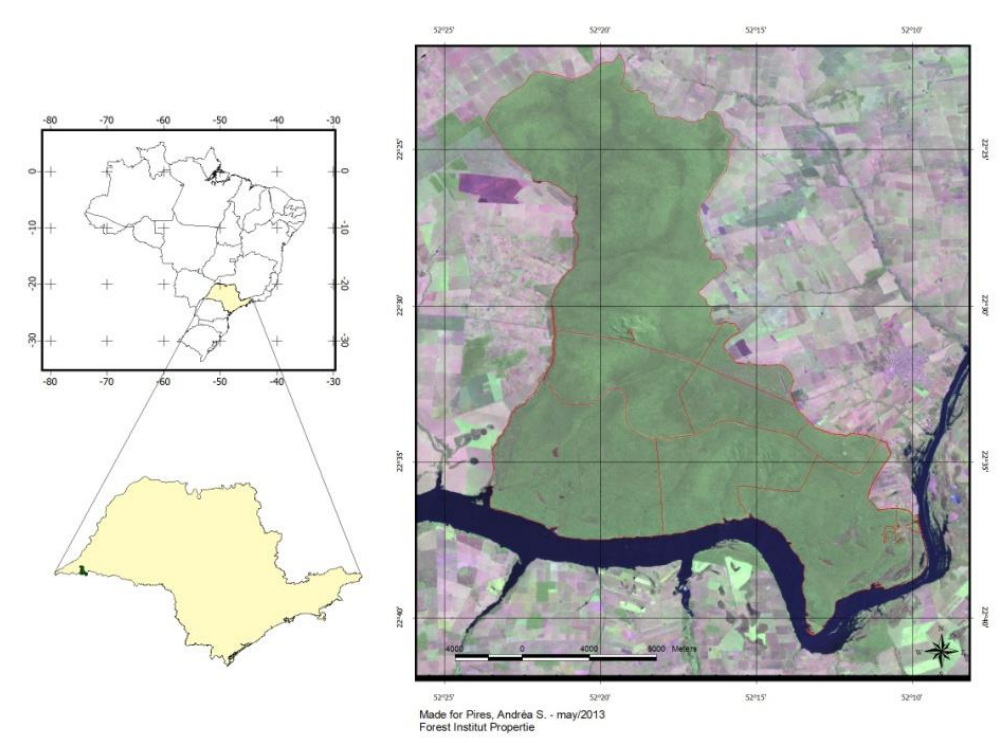

Figura 1: Localização do Parque Estadual do Morro do Diabo. Fonte: PEMD/IF

Sua flora apresenta peculiaridades, como a existência em seu interior de uma pequena mancha de vegetação xerofítica, com a presença de populações de duas espécies de Cactaceae: Cereus hildmanianus (mandacaru) e Praecereus euchlorus (xique-xique), que conferem à vegetação um aspecto de mosaico. Contudo, é a maior reserva de "perobas rosa" (Aspidosperma polyneuron) do sudeste brasileiro, conformando assim um importante banco genético dessa espécie arbórea de madeira apreciável.

Por situar-se numa região de tensão ecológica, a fauna associada à diversidade florestal é muito rica, assumindo importância ecológica algumas espécies tais como o mico-leão-preto (Leontophitecus chrysopygus), um pequeno primata que já esteve na lista dos animais mais ameaçados de extinção do planeta e que no PEMD possui sua maior população em vida livre. Estão presentes também a Panthera onca, Puma concolor, Leopardus pardalis, Tapirus terrestris, Mazama americana, Alouatta guariba, dentre muitos. São quase 300 espécies de aves, algumas muito raras e extremamente vulneráveis, $40 \%$ do total de espécies encontradas no estado de São Paulo. Uma miríade de 
insetos enriquece a diversidade biológica do Parque, dentre as quais se destacam as mais de 400 espécies catalogadas de lepdópteros, que se destacam em certas épocas do ano (INSTITUTO FLORESTAL, 2006).

$\mathrm{Na}$ atualidade o PEMD possui infra-estrutura básica (com sede, escritórios, hospedaria para turistas, hospedaria para pesquisadores, museu natural, sala de aula e palestras, playground infantil, campo de futebol, 06 trilhas ecológicas interpretativas, veículos, máquinas e outros equipamentos; mínimo recursos humanos); e conta com um plano de manejo (IF, 2006). Por força do Decreto ํㅜ 51.453, de 29 de dezembro de 2006 (SÃO PAULO, 2006), o PEMD passou a ser gerenciado pela Fundação Florestal, que herdou o parque pronto do Instituto Florestal, mas que já apresenta sinais de sucateamento dado à falta de investimentos.

O plano de manejo é o documento guia para a tomada de decisão na gestão e atribui ao PEMD os seguintes objetivos:

1. Proteger a maior amostra de Mata Atlântica de Interior do Estado de São Paulo, sua biodiversidade e os recursos genéticos de que dispõe,

2. Proteger e conservar a maior população de Leontophitecus chrysopyguslivres na natureza,

3. Proporcionar condições para o desenvolvimento de pesquisas científicas sobre o ecossistema protegido, assim como suas interações com o entorno, condizentes com a categoria de manejo e com o zoneamento proposto,

4. Propiciar condições para atividades de educação e interpretação ambiental sobre os recursos protegidos na Unidade, apoiando as iniciativas para a implantação do ecoturismo regional.

\section{Análise do Programa de Uso Público}

Esta análise baseia-se no resgate das iniciativas, projetos e metas realizadas ao longo dos anos após a transformação da área em parque estadual em 1986, o que se fez consultando artigos (PÁDUA; TABANEZ, 1997; PÁDUA; TABANEZ, 1998) e relatórios internos, o plano de manejo (INSTITUTO FLORESTAL, 2006) e o testemunho verbal de funcionários do parque, com maior atenção aos envolvidos nos trabalhos com o público. As informações primárias advindas dos funcionários foram obtidas através de entrevistas semiestruturadas e reuniões informais, aspecto que ajudou a entender as possíveis etapas e como e quais estratégias foram adotadas para o desenvolvimento das atividades de uso público no período.

A partir dessas fontes foi possível traçar um sucinto histórico das atividades de uso público no PEMD, que se relacionam a diferentes momentos de gestão da área e aos interesses e conhecimentos dos seus gestores à época, como se verifica no Quadro 1. 
Quadro 1: Histórico do Programa de Uso Público do PEMD, recorte temporal 1984-2004.

1984 a 1986 - a CESP, IF, CPRJ, FBCN e Fundação Parque Zoológico de São Paulo fazem campanhas para a proteção e conservação do mico-leão-preto na região em função do desmate de 2000ha do PEMD pela UHE de Rosana.

1986 - ocorreu um evento organizado pelos técnicos do Instituto Florestal, lotados na área, em conjunto com a prefeitura municipal e a Cesp, denominado "Semana da Árvore". Este evento contou com palestras de técnicos, conferências de docentes de universidades da região e uma exposição de madeiras nativas do PEMD.

1986 a 1988 - abertura da trilha da 'Lagoa Verde'. Ocorriam visitas organizadas muito esporádicas e sem monitoria.

1988 - contratação de um profissional com dedicação integral para a estruturação de atividades voltadas ao público. O "programa" visou apenas um foco, a pesquisa com o Leonthopitecus chrysopygus.A trilha 'Lagoa Verde' passa a se chamar 'mico-leão-preto'

1989 - estudos para abertura da trilha do morro do diabo ao público visitante: Mapeamento, diagnóstico ambiental e interpretação.

1990 - encerramento do contrato do profissional e tomada de atividades por parte da nova chefia da unidade.

1990 a 1991 - atividades voltadas à recepção de visitantes, cursos de capacitação em Educação Ambiental para os professores da região do Pontal do Paranapanema, através da Delegacia Regional de Ensino. Foram realizados um total de 4 cursos de média e longa duração.

1992 - mudança na administração da área. Ocorrência de conflitos de gestão, levando ao cancelamento de visitas e um "fechamento" da área à comunidade.

1994 - troca de administração, onde o profissional que assumiu o cargo herdou os conflitos gerados pela gestão anterior.

1996 - aparecimento de organização não-governamental, que aproveitando a permissividade de gestores complacentes do Estado, dominou as áreas de uso público e pesquisa do PEMD.

2000 -nova administração assume a gestão da área. Entretanto, o responsável não estava locado na área e sim em outra AP, distante $220 \mathrm{Km}$. A visitação atende aos interesses de projetos específicos de pesquisa.

2004 - fixação de dois pesquisadores especialistas em AP na gestão do PEMD. Visitação em descenso.

2005 - após oito anos de ingerências no Programa de Uso Público ocorre o rompimento das relações institucionais, entre ONG e Instituto Florestal. Inicia-se a reestruturação do PUP PEMD, com reunião entre direção da área protegida e stakeholders da região para definição de ações e cronograma de execução, com objetivo de atrair a população para dentro da área.

Fonte: IF (2006), funcionários e documentos internos do Parque.

Assim, de modo descontinuo o PEMD vem oferecendo opções de lazer, recreação e conhecimento ambiental através de caminhadas por trilhas, campeonatos esportivos, festivais culturais, promoção de cursos e palestras para a comunidade estudantil, etc. com objetivo de promover uma articulação positiva com a comunidade local/regional. Nesta linha de tempo cabe ressaltar que a organização responsável pelo PEMD até o ano 2006 foi o Instituto Florestal; a partir de 2007 passou a ser a Fundação Florestal, sendo que os gestores continuaram sendo os pesquisadores do IF lotados no parque, formato administrativo mantido até o ano 2012, quando a direção da Fundação Florestal 
decidiu romper com os trabalhos em andamento. Ambas instituições estão ligadas à Secretaria de Estado do Meio Ambiente de São Paulo.

Percebe-se pelo gráfico de visitação (Figura 2) uma oscilação na quantidade de visitantes até o ano de 2004, o que nos permitiu inferir sobre a existência de problemas que forçavam os resultados a não se equalizarem com o potencial receptivo da área naquele momento. Em primeiro lugar a inexistência de um plano de manejo e a instabilidade dos profissionais gestores no período analisado foram dois fatores de ordem técnico-administrativa, que influenciou significativamente na fragmentação e desorganização das atividades de uso público, impedindo às pessoas uma visão integrada da área protegida e seu entorno e inviabilizando a estruturação de planos operacionais de médio e curto prazo e a continuidade executiva dos mesmos.

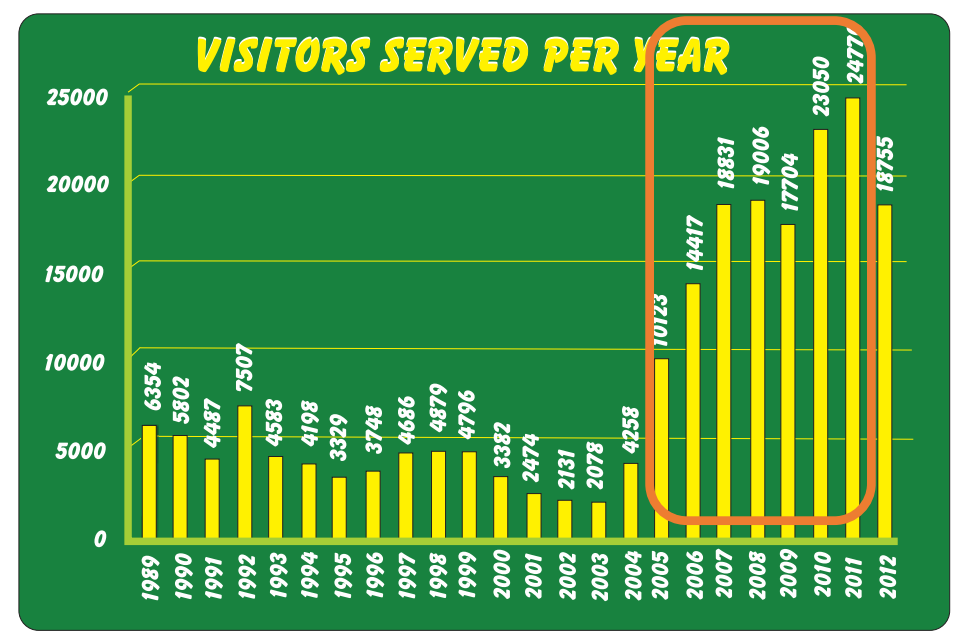

Figura 2: Visitantes atendidos desde a abertura do PEMD ao público, com o recorte temporal a partir da restruturação. Fonte: Pires e Faria ( 2013).

Outra causa detectada foi a insuficiência de capacidades para a gestão da categoria II da UICN por parte daqueles gestores, fator que se não incidiu diretamente sobre todos os profissionais que por esta função passaram lhes foi impedido de manifestar boas práticas de manejo e gestão em função da presença apenas periódica na área, implicando numa visão distorcida das prioridades de gestão da categoria e o não aproveitamento dos recursos de modo adequado.

Um aspecto curioso foi o surgimento de uma parceria, nos anos de 1996, entre a instituição estatal gestora com uma organização não governamental, que a pretexto de fazer pesquisas e educação ambiental se instalou na sede do PEMD por oito anos. A permanência da ONG dentro do parque gerou muitos resultados para seus interesses, alguns comuns ao parque, mas a análise da Figura 2, revela que no período da sua atuação a elevação na quantidade da 
visitação foi muito modesta e volta a cair no ano 2000, evidenciando uma tendência anormal de acontecer em parques ou que a 'parceria' não surtia os resultados desejados.

Este evento foi citado por se percebê-lo como uma importante ingerência administrativa que assediava os destinos do parque, atrelando o seu desenvolvimento aos interesses da organização externa. Ademais, algumas das atitudes tomadas por tal organização eram flagrantemente ilegais e sem respaldo oficial, como a criação e gerenciamento de um 'fundo verde' a partir de recursos de hospedagem do Parque. A falta de efetiva transparência da parceria, de diretrizes políticas consolidadas para o setor e de respaldo institucional aos gestores quando desta ingerência gerou um juízo de valor distorcido numa parcela da comunidade local, atribuindo-se à ONG as benesses e ao Estado a omissão e problemas, um grave condicionante a ser considerado.

Por seu turno, a eficácia de gestão detectada demonstrou que o parque apresentava sérios problemas para uma gestão efetiva naquela ocasião (FARIA, 2002; FARIA, 2004): "A área carecia de um plano de manejo moderno, precisa mais investimentos financeiros, melhorar o nível de capacitação da administração e do corpo de funcionários e a designação e/ou contratação de um ou dois técnicos para trabalharem com a parte de pesquisa e uso público". Segundo o autor, a solução deste último fator incidiria diretamente sobre a melhoria da qualidade de vários indicadores avaliados.

Em face deste cenário, em 2005 empreendeu-se o início do que denominamos 'reestruturação', apesar de nenhuma estrutura orgânica de fato existir, pois não havia uma organização sistêmica da administração e dos programas de gestão.

Os parâmetros que nortearam e justificaram a 'reestruturação' foram a falta de uma estrutura efetiva dedicada ao PUP; as considerações programáticas trazidas pelo plano de manejo, que havia sido terminado fazia pouco tempo; o potencial latente que a área protegida apresentava, haja vista que as atividades e visitas praticadas até aquele momento estavam aquém da capacidade instalada na unidade; as demandas próprias da rede de ensino público regional, cujas manifestações ocorriam nas reuniões do Comitê de Bacias Hidrográficas regional, e a possibilidade dos gestores conseguirem recursos financeiros advindos de compensações ambientais ${ }^{3}$ e financiamento de projetos.

Sublinhe-se que a imagem que os escritórios centrais tinham do parque era extremamente negativa, seja pelo seu distanciamento da sede e as dificuldades de comunicação no passado, seja pelos históricos conflitos pela

\footnotetext{
${ }^{1}$ Compensação Ambiental é um mecanismo financeiro previsto na legislação ambiental brasileira que visa compensar os efeitos de impactos não tigáveis ocorridos quando da implantação de empreendimentos, identificados no processo de licenciamento ambiental. Estes recursos são destinados às áreas protegidas para a consolidação do Sistema Nacional de Unidades de Conservação da Natureza- SNUC.
} 
posse das terras do território em que se situa ou mesmo pelo seu nome e as superstições inerentes da sociedade. Havia a forte necessidade de mudar esta realidade e os esforços deveriam ser direcionados às atividades que alavancassem o desfazimento daquela imagem negativa. Um programa de uso público sob o lema 'Popularizar para Conservar' era a saída.

\section{Estruturação do PUP}

A estruturação do programa realizou-se basicamente mediante a coleta de opiniões dos funcionários do parque, de pessoas participantes do Conselho Consultivo ${ }^{4}$ do parque, diretores de escolas e stackholders da cidade, visando a construção de um cenário possível de ser alcançado segundo as capacidades de manejo daquele momento, pois via de regra os planos de manejo expressam propostas generalistas que às vezes não se enquadram nas realidades locais (MILANO, 2013), constrangendo e desestimulando pessoas.

Ou seja, partiu-se do cenário que havia, decrépito, envolveu-se os atores executores e os atores beneficiários para se delinear o futuro, com objetivos e metas de curto e longo prazos e com o cuidado para que estes não fossem excessivamente vagos ou ambiciosos. Em grande medida isso ocorreu por meio de reuniões estruturadas com este fim e 'chuva de ideias', porém encontros e conversas informais também foram considerados (Figura 3).

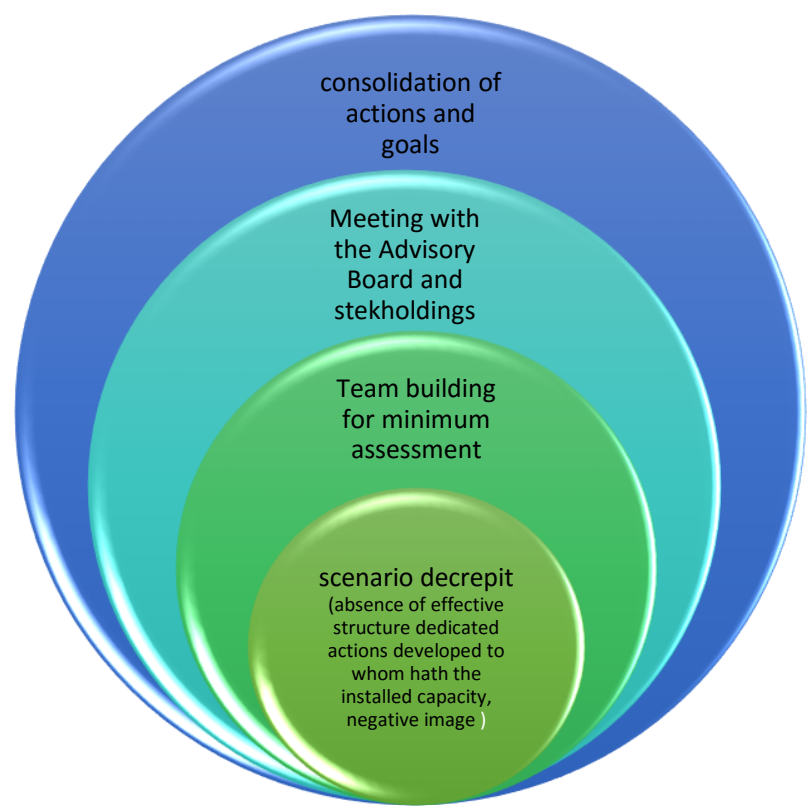

Figura 3: Procedimento metodológico para as intervenções no Programa de Uso Público.

Fonte: Pires e Faria (2013)

\footnotetext{
2Uma importante inovação do SNUC é a previsão de participação da sociedade através dos conselhos gestores - consultivos e deliberativos, conforme a categoria - que assessoram a gestão da unidade. Os conselhos devem ter representação paritária de órgãos públicos e da sociedade civil, contribuindo para a transparência da gestão da área protegida.
} 
Como o PUP não possuía uma equipe formal dedicada exclusivamente às suas atividades, durante o processo de análise para a intervenção compôsse uma equipe mínima com funcionários com perfil satisfatório ao tema, de maneira tal que a participação destes gerasse ao final uma equipe consolidada e ciente das responsabilidades a serem tocadas dali em diante.

Com as informações coletadas estruturou-se uma matriz de partes interessadas, relacionando as características do grupo/organização, interesses, expectativas, potencialidades, debilidades e suas implicações no programa. A formalização dos problemas relacionados à visitação pública, estabelecendo-se suas causas e efeitos foi realizado conforme a metodologia preconizada pela Comisión Europea-EuropeAid (1993), European Commission (1999) e EUROPARC (2002),posibilitando matizar a relevância e incidência dos problemas existentes, detectar novos problemas e eliminar aqueles de menor incidência real.

Cada uma das tensões detectadas foi sintetizada em uma ficha, detalhando-a em: onde e como atuar, a escala espacial e temporal em que se manifesta, a tendência observada, a gravidade do problema e as fontes de informação utilizadas.Com isso traçou-se uma árvore de problemas e outra de objetivos, visando a facilitar o delineamento de ações e metas para o uso público, ou o alcance do cenário possível.

O comprometimento do quarto objetivo de manejo do parque estava intrinsecamente ligado a quatro problemas de base, quais sejam: i) Desvalorização da área protegida, por desconhecimento da comunidade do potencial existente para o lazer e aprendizado; ii) Ausência de ações que integrassem e trouxessem a comunidade para dentro da área de modo cidadão e plural; III) Ingerência de organização externa nas atividades de uso público, à revelia dos projetos e programas oficiais; IV) Ausência local de técnico (ponto focal) da organização gestora para o uso público.

Esses problemas levavam a dificuldades mais específicas como a falta de estruturação e monitoramento da recepção dos visitantes, desorganização na informação transmitida sobre o Parque, benefício restrito a pequenos grupos ligados aos interesses da organização externa, descontinuidade das ações, ausência de um calendário de eventos, instabilidade dos recursos e insumos básicos, entre outros.

A partir da árvore de objetivos identificou-se que para assegurar a coerência do programa de uso público e o pleno desenvolvimento das atividades propostas pelo plano de manejo as ações deviriam ser incisivas e imediatas, a fim de trazer a população para dentro da área.

Os componentes gerenciais e programáticos priorizados para intervenção foram: 
> obtenção de um técnico para coordenar o PUP;

$>$ investimento em conhecimento, na formação permanente da sua equipe e melhoria da qualidade receptiva;

$>$ planejamento de eventos sócio-ambientais para e com a comunidade;

$>$ desenvolver materiais e equipamentos para a comunicação e educação ambientais;

> aproximação e parcerias com outras organizações, incluindo a mídia local/regional visando ser fonte de noticias positivas e divulgar 0 parque e, por último,

$>$ adotar mecanismos para o monitoramento do programa.

\section{RESULTADOS}

Tal como já mencionamos, apresentam-se aqui os resultados do recorte temporal 2005-2012, enquanto vigeu o "Popularizar para Conservar".

Como se depreende da análise das atividades de uso público até o ano 2004, não havia uma estrutura orgânica do parque dedicada exclusivamente ao planejamento e orientação dos trabalhos com os visitantes e às relações com as comunidades vizinhas, redundando em apatia e causando as oscilações quantitativas observadas no gráfico de visitação (Figura 2). Assim, das primeiras medidas visando sanar tal lacuna foi a efetivação de um técnico-pesquisador do Instituto Florestal para conduzir a coordenação do PUP e a obtenção de um número mínimo de guias ou monitores ambientais, aqueles que de fato conduzem os visitantes no parque.

A equalização dos conhecimentos dessa equipe foi tratada de modo prioritário, mediante a leitura e discussão de variados textos relativos às questões ambientais, mas fundamentalmente todos deveriam conhecer sobre 0 parque, sua história intrincada à história do desbravamento da região, suas características ambientais, sua importância no contexto estadual, nacional e internacional, as espécies da fauna e da flora mais significativas, as lendas e curiosidades populares, etc. etc. Ademais, procurou-se estabelecer uma orientação básica de como se proceder nas diversas situações que pudessem ocorrer em contato com o público, fomentando mais autoconfiança e propriedade à equipe.

O processo de análise do programa propiciou uma mudança na abordagem das palestras com temas ecológicos abrangentes, construção de materiais lúdico-educativos, elaboração de materiais interpretativos, atividades diferenciadas por faixas etárias e públicos, melhorando a qualidade da informação transmitida. Com base no levantamento do perfil do visitante delinearam-se atividades direcionadas a diferentes faixas etárias, além de manter uma estreita ligação da teoria com a prática nas trilhas interpretativas, ou seja, no Centro de Visitantes os conhecimentos básicos de ecologia eram 
transmitidos em formato audiovisual e posteriormente se mostra na prática de forma descontraída.

Iniciou-se um processo de tomada de decisão com maior equidade na governança do programa, por meio do envolvimento efetivo dos membros da equipe e, quando possível e necessário, de cidadãos. Dentre muitas das atividades iniciais houve uma que animou a equipe e estreitou seus laços: a adaptação dos espaços físicos do PUP. Os escritórios administrativos do parque foram realocados e no seu lugar surgiu o Museu Natural, com salas de exposição contendo peças taxidermizadas de animais, mapas e maquetes do parque, escritório para a equipe, biblioteca ambiental básica e banheiros. O local que anteriormente abrigava a exposição passou a ser um espaço de uso múltiplo, com sala de aula e projeções e espaço de vivência para o público infantil.

Instituiu-se o conceito e rotinas de monitoramento e a avaliação (IUCN, 2000) das atividades como forma de melhoria constante dos serviços prestados e o estimulo à realização de pesquisas básicas visando gerar conhecimentos relacionados ao uso público do parque, de modo que as informações auxiliassem na melhoria das atividades, na regulação dos usos e conservação de recursos. Isto se obteve mediante uma parceria informal com a Universidade Estadual de São Paulo (UNESP, campus Rosana-SP), estimulando-se os professores do curso de Turismo a utilizarem o PEMD como material de pesquisa, resultando na cobertura de várias lacunas observadas e muitas informações gratuitas para o PUP, além das investigações produzidas pelos técnicos do próprio parque, conforme citado nas referências bibliográficas deste trabalho.

Foram pesquisas dirigidas ao atendimento ao público e à investigação de aspectos relacionados aos atrativos naturais da paisagem do parque, as opiniões e sugestões (percepção) advindas dos turistas e vizinhos da AP, avaliações da eficácia da gestão da área e a aplicação de rotinas de auditoria e certificação para o turismo, de modo tal que essas informações realimentaram a gestão para que a mesma pudesse melhorar sua eficiência embasada em dados reais. Aliás, cabe revelar que os resultados de uma tese de doutoramento auxiliaram, sobremaneira, nos passos iniciais do novo programa de uso público, dado que o pesquisador analisou critérios e parâmetros para a certificação de atividades turísticas responsáveis no PEMD, abarcando as dimensões 'instituição', 'ambiental', 'infraestrutura', 'social' e as 'condições gerais' da área protegida para uso ecoturístico. Essas dimensões foram avaliadas por meio de indicadores quali-quantitativos, cujo resultado alcançou apenas $60 \%$ da pontuação distribuída, permitindo ao autor indicar uma série de recomendações especificas para o setor, que foram paulatinamente adotadas pela administração da área(Oliveira, 2005).

O monitoramento iniciado começou a produzir satisfação nos membros da equipe, pois todos puderam enxergar os reais resultados de suas atuações, sendo visível o alumbramento de todos em face do esperado e desejado 
aumento no número de visitantes ao parque, que apenas no primeiro ano subiu $150 \%$, acumulando $600 \%$ em 6 anos de atividades.

Verifica-se através dos registros que as instituições de ensino (escolas, colégios, universidades privadas e públicas) e outros grupos organizados (associações, igrejas, clubes de serviço, etc.) foram os que mais procuraram o Parque no período de 2005 a 2009. A partir de 2010, além do público escolar, famílias e grupos de ecoturistas começaram a procurar o PEMD como alternativa de lazer nos finais de semana e feriados prolongados e como atrativo turístico nas férias escolares.

Uma das melhores formas de divulgar a área e envolver a comunidade foi através da criação, planejamento e execução de eventos que permitam a sensibilização dos cidadãos sobre a sua existência e importância, como um espaço de uso público democrático para a manifestação da cidadania e refrescamento do espírito, ademais da percepção de benefícios oriundos das políticas públicas dedicadas à conservação ambiental.

A estratégia empregada para o sucesso dos eventos programados foi a edificação de uma agenda comum com diretores das escolas, representantes do comercio, membros do conselho consultivo, prefeitura e outras organizações de atuação local ou regional com atuação ajustada ao seu desenvolvimento e conservação, considerando-se o zoneamento ambiental e as normas de gestão distinguidas em Instituto Florestal (2006).

Os eventos vão desde programas especiais de férias, gincanas ecológicas locais e regionais, exposições itinerantes, programação especial para portadores de necessidades especiais, acampamentos interativos, encenações teatrais nas trilhas, exposições de artesanatos, entre outros, nos quais figura como foco a paisagem e a biodiversidade do PEMD, conforme Pires e Faria (2013).

Vale destacar que a pró-atividade da equipe do parque rendeu a instituição de uma Lei municipal que define a data de criação do Parque, 29 de outubro, como o dia de comemorar seu aniversário e que alguns eventos planejados pelo PUP e comunidade passaram a fazer parte do calendário de eventos do Município de Teodoro Sampaio, a exemplo da exposição de artesanato. Também em função da qualidade dos trabalhos de educação ambiental, o PUP foi agraciado em 2008 com o prêmio "Práticas Significativas", oferecido pelo Fundo Estadual de Recursos Hídricos-FEHIDRO.

$\mathrm{Na}$ medida em que as ações do "Popularizar para Conservar" eram engendradas, iniciou-se também o processo de planejamento e elaboração de materiais para comunicar com os visitantes compreendendo folders e cartazes, cartões postais, cartilhas, apresentações de palestras, interpretação de trilhas, guias para visitantes, como os descritos na Tabela 1. 
Tabela 1: Materiais didáticos produzidos no período de 2005 a 2012.

\begin{tabular}{|c|c|c|}
\hline $\begin{array}{l}\text { TIPO DE } \\
\text { MATERIAL }\end{array}$ & TEMÁTICA & DESCRIÇÃO \\
\hline Palestra & $\begin{array}{l}\checkmark \text { O Parque Estadual do Morro do Diabo - } \\
\text { sua importância no contexto local e } \\
\text { regional } \\
\checkmark \text { A Biodiversidade no Mundo,no Brasil e no } \\
\text { PEMD } \\
\checkmark \text { A Água - conservação, disponibilidade e } \\
\text { usos } \\
\checkmark \text { Mudanças Climáticas Globais, Regionais e } \\
\text { Locais } \\
\checkmark \text { Aspectos Históricos do Pontal do } \\
\text { Paranapanema e do PEMD } \\
\checkmark \text { Ecologia da Paisagem } \\
\checkmark \text { Processos e Relações Ecológicas - } \\
\text { mimetismo, camuflagem, cadeia alimentar, } \\
\text { mutualismo, comensalismo, parasitismo, } \\
\text { sucessão ecológica } \\
\checkmark \text { Relação Planta-Animal } \\
\checkmark \text { Vegetacão do PEMD }\end{array}$ & $\begin{array}{l}\text { Cada tema, antes mesmos de } \\
\text { utilizado com os grupos } \\
\text { escolares, foi apresentado à } \\
\text { equipe a fim que todos } \\
\text { buscassem mais informações } \\
\text { para serem transmitidas } \\
\text { durante as caminhadas, } \\
\text { palestras e atividades lúdico- } \\
\text { educativas, uma maneira } \\
\text { integradora de capacitação e } \\
\text { transmissão de informação } \\
\text { diferenciada para os } \\
\text { visitantes. }\end{array}$ \\
\hline $\begin{array}{l}\text { Folder, } \\
\text { cartilhas e } \\
\text { informativos }\end{array}$ & $\begin{array}{l}\checkmark \text { Trilhas do Parque Estadual do Morro do } \\
\text { Diabo } \\
\checkmark \text { Fauna do PEMD - Espécies Ameaçadas - } \\
\text { série de } 8 \text { folders com as principais } \\
\text { espécies existentes na área; } \\
\checkmark \text { Convívio 'Homem e Fauna' para conflitos } \\
\text { com predadores no entorno } \\
\checkmark \text { 'Nossa Mistura \& Diversão' dedicado à } \\
\text { pesca responsável } \\
\checkmark \text { Motorista Responsável dedicado às } \\
\text { campanhas na rodovia SP-613 } \\
\checkmark \text { Guia do Visitante da Trilha da Lagoa Verde } \\
\checkmark \text { Guia do Visitante da Trilha do Morro do } \\
\text { Diabo } \\
\checkmark \text { 70 Anos do Parque Estadual do Morro do } \\
\text { Diabo } \\
\checkmark \text { Jornal InfoPemd }\end{array}$ & $\begin{array}{l}\text { O objetivo era distribuir } \\
\text { informações de qualidade a } \\
\text { respeito da área, em ampla } \\
\text { escala e facilitando a } \\
\text { compreensão da área no } \\
\text { momento da visita in loco }\end{array}$ \\
\hline & $\checkmark$ Paisagens do PEMD, série de cartazes; & \\
\hline $\begin{array}{l}\text { Jogos } \\
\text { Educativos }\end{array}$ & $\begin{array}{ll}\checkmark & \text { jogo da memória } \\
\checkmark & \text { cruza parque } \\
\checkmark & \text { coloque o rabo no mico-leão-preto } \\
\checkmark & \text { que bicho eu sou } \\
\checkmark & \text { ajude o mico a encontrar seus filhotes } \\
\checkmark & \text { salve a água do nosso planeta } \\
\checkmark & \text { passeando no parque estadual do morro do } \\
\text { diabo tabela maluca dominó dos bichos } \\
\checkmark \text { pesca parque } \\
\checkmark \text { alfa parque } \\
\checkmark \text { latinha educativa } \\
\checkmark \text { aprendendo com a turma do criança } \\
\text { ecológica }\end{array}$ & $\begin{array}{l}\text { Confeccionados pelos } \\
\text { monitores do PEMD, são } \\
\text { jogos de tabuleiro, com mdf } \\
\text { ou material reciclado, } \\
\text { abordando vários temas } \\
\text { relacionados à fauna do } \\
\text { Parque, } \\
\text { conservação de recursos, } \\
\text { utilizando os mascotes como } \\
\text { personagens principais }\end{array}$ \\
\hline
\end{tabular}

Revbea, São Paulo, V. 10, № 3: 200-220, 2015. 
Um informativo não periódico (InfoPemd), digital e impresso, foi desenvolvido trazendo informações sobre as pesquisas realizadas na área e seus reflexos na gestão, as atividades educativas, os acontecimentos no período, o qual foi amplamente distribuído ao mailing regional, escolas, universidades, pesquisadores e população cadastrada. Vídeos educativos e comemorativos surgiram de maneira inusitada no seio da equipe de uso público, assim como o 'blog' do parque (http://pe.morrododiabo.blogspot.com).

Mas os trabalhos de planejamento de trilhas interpretativas foram os mais produtivos no âmbito da melhoria dos equipamentos para a comunicação ambiental. $\mathrm{O}$ aumento da procura pelo Parque aumentou consequentemente a pressão e impactos sobre os recursos disponíveis para a visitação. Dentro das propostas do plano de manejo e mediante os conhecimentos técnicos disponíveis(STANKEY et al., 1985; GRAEFE et all, 1990; CIFUENTES, 1992; HESSELBARTH et all., 2007), três novas trilhas foram abertas, 'Perobeiras', 'Paranapanema'e 'Barreiro das Antas', com o total de 7,7 quilômetros de percurso, sendo que esta última foi completamente interpretada com 10 painéis graças a um financiamento obtido do Fundo Estadual de Recursos Hídricos FEHIDRO. Por seu turno, a trilha do Morro do Diabo, a mais importante e que conduz ao principal atrativo da área protegida, recebeu tratamento emergencial, foi totalmente restaurada e reinterpretada com a elaboração de 20 painéis com financiamento advindo de uma compensação por danos ambientais no Parque.

Outras estruturas também foram adaptadas para o melhor atendimento do público escolar, como uma sala de vídeo com personagens temáticas, além de recursos pedagógicos de fácil manuseio distribuídos pelos espaços didáticos, tais como terrário, "máquina de chuva para diferentes ambientes (cidade, campo e floresta)", cemitério de animais atropelados pela rodovia que corta a área e jogos educativos utilizando os recursos das trilhas.

Com a intenção de sensibilizar a opinião pública, levar informações acerca do assunto e esclarecer alguns pontos, divulgar eventos e atividades cotidianas, foi criado, em 2008, um perfil no miniblog Twitter (@MorrodoDiabo) e posteriormente um perfil no Facebook (MorrodoDiabo Parque Estadual e Parque Estadual do Morro do Diabo), contendo informações mais detalhadas a respeito da área, hoje todos sem alimentação de informação, por exigência da organização gestora da área. Atualmente o conteúdo deste perfil apresenta o cotidiano do Parque, com fotos e descrições, despertando ainda mais a curiosidade das pessoas, bem como aproxima aqueles que visitam e postam suas fotos e ideias. Ainda no que é a divulgação para a multiplicação das ações positivas, fez-se um trabalho de aproximação com canais de comunicação regional, o que rendeu um grande número de aparições e inserções do parque na imprensa falada, escrita e televisiva. Em comemoração aos 70 anos do PEMD criou-se um blog completo, com várias páginas de informações e artigos a respeito da área (http://pe.morrododiabo.blogspot.com).

Dentro da lógica de intervenção no PUP, dever-se-ia aproveitar todas as oportunidades potencialmente geradoras de resultados que estimulassem um 
olhar para o parque como fonte de saberes. Neste sentido inseriu-se o PEMD em três programas/projetos de políticas públicas encampadas pela Secretaria de Meio Ambiente de São Paulo: "Criança Ecológica", "Lugares de Aprender" e "Trilhas de São Paulo".

O projeto Criança Ecológica, que durou apenas três anos, teve o objetivo de sensibilizar e despertar nas crianças de 08 a 12 anos atitudes capazes de contribuir com a melhoria da qualidade de vida e do meio ambiente, sendo aberta uma trilha especifica com os temas do Projeto, a trilha do 'Barreiro das Antas'. Concomitante desenvolveu-se o projeto Lugares de Aprender, cujo objetivo é promover o acesso de professores e alunos da rede de ensino pública a museus, centros de pesquisa, institutos de arte e cultura e a áreas protegidas como atividade articulada ao desenvolvimento do currículo escolar. Em ambos, de 2009 a 2012 o PEMD atendeu 18.755 pessoas, entre crianças e professores, agregando conhecimento sobre a área, sua biodiversidade e ações de manejo desenvolvidas, pois esse é o maior objetivo da educação ambiental em áreas protegidas.

O projeto Trilhas de São Paulo foi idealizado visando a permitir que os visitantes vivenciem e valorizem a natureza, entendam porque é importante sua conservação e reconheçam que áreas naturais prestam serviços inestimáveis ao homem. São 40 trilhas localizadas em 19 áreas protegidas, divididas em três níveis de dificuldade, para atender os mais diversos públicos e permitir que todos tenham acesso às áreas preservadas. A trilha do Morro do Diabo foi totalmente reinterpretada com fulcro neste projeto.

Evidentemente que não seria possível a intensidade de trabalho em prol da proposta "Popularizar para Conservar" não fosse uma rede de relações organizacionais mantidas desde o início das atividades estratégicas para a reestruturação do programa de uso público do PEMD. A matriz de partes interessadas foi a precursora na identificação das potencialidades das organizações para o planejamento, organização e execução de eventos socioambientais, bem como o apoio financeiro para efetivação dos mesmos, com atuação do Instituto Florestal, Fundação Florestal (gestão 2007-2010), Prefeitura Municipal de Teodoro Sampaio, Policia Ambiental, Policia Rodoviária, Departamento de Estradas de Rodagem, Ministério Público, Odebrecht Agroindustrial, Escolas locais, Comitê de Bacias Hidrográficas do Pontal do Paranapanema, Universidade do Oeste Paulista, Associação Comercial de Teodoro Sampaio, Companhia Energética de São Paulo, Companhia de Saneamento de São Paulo, Instituto Geológico, Museu de Geologia de São Paulo.

Contudo, apesar de alguns parceiros patrocinarem materiais específicos de baixo custo, não seria possível edificar e executar a agenda proposta não fosse a elaboração de projetos para a obtenção de recursos advindos de compensações ambientais. Desta maneira obteve-se dinheiro para a aquisição de equipamentos, materiais, reparos na infraestrutura e, sobretudo, a 
contratação de profissionais e monitores ambientais por um período de quatro anos, acumulando um financiamento de cerca US\$ 535,000,00 (quinhentos e trinta e cinco mil dólares), sem abarcar os custos fixos relativos ao Estado relativos ao pagamento de salários dos funcionários e a manutenção corrente do parque.

Os resultados do 'Popularizar para Conservar' podem ser sintetizados assim:

Tabela 2: Síntese dos resultados conquistados em 8 anos de intervenção.

\begin{tabular}{|c|c|}
\hline Ações/atividades & Números \\
\hline Pesquisas e trabalhos afins & 15 \\
\hline Formação de pessoal & 23 pessoas \\
\hline Materiais didáticos produzidos & 30 \\
\hline Trilhas planejadas & 4 \\
\hline Trilhas implantadas & 3 \\
\hline Trilhas restauradas & 1 \\
\hline Parceiros & 14 organizações \\
\hline Visitantes atendidos & 48,544 pessoas \\
\hline Participantes de eventos & 190 \\
\hline Noticia impressa (jornais e revistas) & 70 \\
\hline Inserção em TV & 67 \\
\hline Inserção em Rádio & \\
\hline
\end{tabular}

\section{CONCLUSÃO}

A situação encontrada no Parque Estadual do Morro do Diabo nos dias que antecederam o início dos trabalhos do "Popularizar para Conservar" mostravam que a área protegida precisava de investimentos fortes para atender os objetivos propostos no plano de manejo, fundamentalmente o quarto objetivo, aquele que the confere uma importante função conceitual da categoria II da IUCN, os parques nacionais e congêneres.

O parque estava subutilizado e não oferecia os benefícios que a sociedade poderia usufruir se houvesse ali um programa de uso público estruturado e dinâmico, calcado na técnica, nos anseios das pessoas e na participação cidadã. A visitação e as práticas lúdicas eram tacanhas e muito subordinadas a um projeto de uma organização não governamental, que transigia indevidamente na gestão do parque, acarretava distorções das missões institucionais e na imagem da área protegida como um bem destinado ao amplo uso comum

As técnicas usadas na análise das atividades de uso público permitiram que as pessoas ligadas diretamente à gestão e parceiros se envolvessem no processo de maneira informal, no entendimento do cenário que existia e no traçado de ações estratégicas claras, pautadas na integração dos programas de 
gestão preconizados no plano de manejo, com vista a implementar uma agenda positiva possível e eficaz.

Nesta direção executou-se na área protegida atividades relativas à interpretação da natureza, educação ambiental, eventos socioambientais, ecoturismo, pesquisa e monitoramento, causando um impacto que, se por um lado não foi aqui alvo de mensuração, é possível aquilatar pelo aumento da visitação, pela produção de materiais didáticos e trabalhos técnico-científicos afins, ademais de transformar o PEMD em fonte de notícias positivas regional.

Um Parque não pode prescindir de conhecimento sobre o público que o visita, a percepção dos vizinhos sobre a conservação da área, as perspectivas futuras para a melhoria da educação ambiental, estudos para fortalecer a conservação da biodiversidade, dentre uma série de outros, que se distinguem conforme as peculiaridades de cada área protegida. Isto porque esses conhecimentos realimentam a gerência, permitindo-lhe melhorar sua eficiência embasada em dados reais.

É impossível se empreender ações exitosas de educação ambiental em áreas protegidas embasados apenas nos orçamentos oficiais, o que pode ser sanado mediante as parcerias e dedicação de esforço para o financiamento de projetos, como relatamos. Por seu turno, a legislação ambiental brasileira prevê compensações ambientais no caso de impactos ao meio ambiente causados por empreendimentos econômicos, oportunidade bem aproveitada no processo da gestão programática relatada.

Numa área protegida como o Parque Estadual do Morro do Diabo (e congêneres) deve-se procurar sempre desenvolver atividades que tragam a comunidade para dentro da mesma, de modo tal que seja incutido nas pessoas o sentimento de pertencimento do espaço protegido, que sobressaia o "eu" responsável e participante facilitador do processo educacional, mesmo que seja em poucos momentos, como em eventos ou andando pelas trilhas em meio às paisagens naturais.

\section{Referências}

BRASIL. Lei Federal n. 9.985, de 18 de julho de 2.000. Diário Oficial da União, P 1-6, 19 de jul. de 2000.Seção I. Regulamenta o artigo 225, $1^{\circ}$ - incisos I, II, III e IV da Constituição Federal, institui o Sistema Nacional de Unidades de Conservação da Natureza e dá outras providências. 2000.

CGEAM - COORDENAÇÃO GERAL DE EDUCAÇÃO AMBIENTAL/IBAMA. Relatório de Atividades da Coordenação Geral de Educação Ambiental-CGEAM/DISAM-2003/2006. [s.n.]: Brasília: CGEAM. 2007.

CIFUENTES, M. Determinación de Capacidad de Carga Turística em áreasprotegidas. Centro Agronômico Tropical de Investigación y Enseñanza CATIE, Turrialba, Costa Rica, 1992. 
COMMISSION OF THE EUROPEAN COMMUNITIES. Project Cycle Management. Integrated approach and logical framework. Evaluation Unit, Directorate General for Development, Commission of the European Communities, Bruxelas. 1993.

EUROPARC-España. Plan de Acción para los Espacios Naturales Protegidos del Estado Español. Fundación Fernando González Bernáldez, Madri. [http:Ilwww.europarc-es.org]. 2002.

EUROPEAN COMMISSION. Guidelines for drawing up terms of reference for evaluations. Evaluation methodology, criteria and suggested layout for evaluation reports. Joint Relex Service for the Manteinance of Community Aid to Non-Member Countries (SCR), SCR/F/5D(98), Bruxelas. 1999.

EUROSITE. Guía Europea para la Preparación de Planes de Gestión de espacios naturales. Consellería de Medi Ambient, Ordenació del Territoti i Litoral. Govern Balear, Palma de Mallorca. 1998.

FARIA, H.H. Estado da gestão de três unidades de conservação de São Paulo inseridas nos domínios da Mata Atlântica: Parques Estaduais da llha do Cardoso, de Carlos Botelho e do Morro do Diabo. In: III CONGRESSO BRASILEIRO DE UNIDADES DE CONSERVAÇÃO. Anais ...Fortaleza, CE. 22 a 26 de setembro de 2002. ANAIS. p. 289-303. 2002.

FARIA, H.H. Eficácia de gestão de Unidades de Conservação gerenciadas pelo Instituto Florestal de São Paulo, Brasil. Tese de doutoramento. Depto. Geografia. UNESP. Presidente Prudente, SP. 2004. 401p.

IBAMA/GTZ. Roteiro Metodológico para o Planejamento de Unidades de Conservação de Uso Indireto. Documento interno. Brasilia, 1996.

GRAEFE, A.R.; KUSS, F.R.; VASKE, J.J. Visitor impact management theplanning framework. Washington D.C.: National Parks and ConservationAssociation. 1990.

HESSELBARTH, W.; VACHOWSKI, B.; DAVIES, M.A. Trail Construction and Maintenance - Notebook 2007. United States Departament of Agriculture, Forest Service and Technology \& Development Program. Tradução de Sergio Beck. Secretaria de Meio Ambiente. São Paulo, BR. 2009. 171 p.

INDRUSIAK, C.B., 2000, Metodologias para avaliação do perfil do público em programas de Educação Ambiental para áreas protegidas. Anais do II CONGRESSO BRASILEIRO DE UNIDADES DE CONSERVAÇÃO, vol.II, pp. $243-247$.

INSTITUTO FLORESTAL. Plano de Manejo do Parque Estadual do Morro do Diabo. Coord. Editorial de Faria, H. H. de \& Pires, A. S. Editora Viena. Santa Cruz do Rio Pardo, SP. 2006.311 p. 
IUCN. Evaluating Effectiveness. A Framework for Assessing the Management of Protected Areas. Org. by HOCKINGS, M.; STOLTOn, S.; DUDLEY, N. G., Switzerland and Cambridge, UK: IUCN. Working Group on Management Effectiveness, 2000.121p

JACOBI, P. Educação ambiental, cidadania e sustentabilidade. Cadernos de pesquisa, ํ‥ 118, março. 2003

LOUREIRO, C.F.B. Educação ambiental e gestão participativa na explicitação e resolução de conflitos. Gestão em Ação, Salvador, v. 7, n. 1. 2004.

LOUREIRO, C.F.B. et al. Educação ambiental e gestão participativa em unidades de conservação. 2ª ed. Rio de Janeiro: IBAMA / IBASE. 2005.

MAGRO, T.C. Impactos do Uso Público Em uma Trilha no Parque Nacional do Itatiaia. Tese de Doutorado. Universidade de São Paulo, Escola de Engenharia de São Carlos (Ciências da Engenharia Ambiental). São Carlos, 199 9, 135p.

MAYER, M. Educación ambiental: de la accion a la investigación. Enseñanza de Las Ciencias, Barcelona, V.2, №. 16, p. 217-231. 1998.

MCNEELY, J.A. (ed.); SCHUTYSER, F. (ed.). Protected areas in 2023: scenarios for an uncertain future. IUCN Gland (Suiza) 51p. 2003

MENGHINI, F.B.; MOYA-NETO, J.; GUERRA, A.F.S. Interpretação ambiental. In: FERRARO-JUNIOR, L.A. Encontros e caminhos: formação de educadoras(es) ambientais e coletivos educadores. Brasília: MMA. v. 2. p. 209218. 2007.

MILANO, M.S. Unidades de Conservação no Brasil: Mitos e Realidade. Anais do 30 CONGRESSO INTERNACIONAL DE DIREITO AMBIENTAL: A PROTEÇÃO JURÍDICA DAS FLORESTAS TROPICAIS.... 30 de maio a 02 de junho de 1999. São Paulo, SP: Ed. Antonio Hermann de Vasconcelios e Benjamin, Vol. I. p. 307-316. 1999.

MILANO, M.S. Planos de Manejo de UCs III: hora de virar o jogo. OEco on line. Publicado em 03 de abril de 2013. Acessado em 04/04/2013.http://www.oeco.org.br/convidados-lista/27052-planos-de-manejode-ucs-iii-hora-de-virar-o-jogo.

MILLER, K. R. Planificación de parques nacionales para el ecodesarrollo en Latinoamérica. España: FEPMA,1980. 500 p.

OLIVEIRA, S. D. Certificação de atividades turísticas responsáveis em Unidades de Conservação. Estudo de caso: O Parque Estadual Morro do Diabo, Pontal do Paranapanema, SP. 2005. 210 f. Tese de Doutorado - Programa de PósGraduação em Engenharia de Produção - Universidade Federal de Santa Catarina, Florianópolis, 2005.

PADUA, S.; TABANEZ, M. Uma abordagem participativa para a conservação de áreas naturais: educação ambiental na Mata Attântica. Anais do CONGRESSO DE UNIDADES DE CONSERVAÇÃO. Curitiba, Paraná: Universidade Livre do 
Meio Ambiente, Rede Nacional Pró Unidades de Conservação e Instituto Ambiental do Paraná: Volume 2. 371-379. 1997.

PÁDUA, S.; TABANEZ, M. (Orgs.). Educação Ambiental: caminhos trilhados no Brasil. Ipê: São Paulo, 286p. 1998.

PIRES, A.S; FARIA, H.H. Restructuring Program For Public Use And Environmental Education The Morro Do Diabo State Park, Sao Paulo, Brazil. IN: WORLD ENVIRONMENTAL EDUCATION CONGRESS. Anais... complete paper. Marrakesh, 2013/9-14 June. Moroco. http://www.weec2013.org/index.php?option=com content\&view=article\&id=385 \&ltemid $=573 \&$ lang $=$ es

FARIA, H.H.; PIRES, A.S. Implicações dos Conselhos Consultivos na Gestão de Unidades de Conservação. Periódico Eletrônico "Fórum Ambiental da Alta Paulista". v. 9, n. 3 (2013). p. 33-53. Associação Amigos da Natureza da Alta Paulista. Tupã. 2013.

QUINTAS, J.S. Educação no processo de gestão ambiental: uma proposta de educação ambiental transformadora e emancipatória. In: LAYRARGUES, P. P. Brasília: MMA. p. 113-140. 2004.

SAMMARCO, Y.M. Percepções socioambientais em unidades de conservação: o jardim de Lilith?. Dissertação (Mestrado) - Programa de pós-graduação em engenharia ambiental, Universidade Federal de Santa Catarina, Florianópolis. 2005.

STANKEY, G.H.; COLE, D.N.; LUCAS, R. C.; PETERSEN, M. E.; FRISSELL, S. $S$. The Limits of Acceptable Change (LAC) system for wilderness planning. ForestService. United States Department of Agriculture. General Technical Report INT- 176,p 1-37, 1985

TAKAHASHI, L. ;Y. Caracterização dos visitantes, suas preferências e percepções e avaliação dos impactos da visitação pública em duas unidades de conservação do Estado do Paraná. 1998. 129 f. Tese Doutorado em Ciências Florestais - Universidade Federal do Paraná, Curitiba.

VALENTI, M.W.; OLIVEIRA, H.T.; DODONOV, P.; SILVA, M.M. Educação ambiental em unidades de conservação: políticas públicas e a prática educativa. Educação em Revista. Educ. rev. vol.28 no.1 Belo Horizonte http://dx.doi.org/10.1590/S0102-46982012000100012 . Mar. 2012. 